\title{
ANÁLISE DA VIOLÊNCIA DO BULLYING DE ACORDO COM RELATOS DOS ADOLESCENTES NOS BLOGS DA INTERNET
}

\author{
Jales Silva Barreto \\ Marina Kohlsdorf \\ (Centro Universitário UNICEUB - Brasília -DF)
}

\begin{abstract}
Resumo
Este estudo apresenta uma análise dos relatos online de adolescentes vítimas do fenômeno do bullying. Foram pesquisados relatos em vários sites, blogs da internet, identificando adolescentes que passaram como vítimas por esta agressão nos vários contextos: físico, verbal, relacional e cyberbullying. Foram selecionados 61 relatos, categorizados em temas como: agressão verbal, violência física, intimidação pela Internet, intimidação relacional e violência sexual. Os dados evidenciam o bullying como um fenômeno que tem crescido nos diversos ambientes e das mais diversas modalidades, ocasionando o processo cultural de violência nos vários contextos sociais.
\end{abstract}

Palavras-chave: bullying; mobbing; violência.

\begin{abstract}
Analysis of bullying violence according to reports from adolescents on Internet blogs

This study analyzes the online teenagers' stories regarding bullying. Several reports were searched on the internet, including blogs, identifying teenagers who went through this aggression in many contexts: physical, verbal, relational and cyberbullying. Therewith, 61 reports were accepted, and the following categories were found: verbal aggression, physical violence, internet intimidation, relational intimidation and sexual violence. Data highlighted bullying practices as a phenomenon that has grown in different environments and in many different ways, causing the cultural violence process in various social contexts.
\end{abstract}

Keywords: bullying; mobbing; violence.

\section{Introdução}

O bullying é traduzido como um fenômeno de intimidação. É um processo mundial e os seus estudos foram iniciados sobre esta prática na Noruega, por Dan Olweus em 1973. Em 1989, o pesquisador Roland identificou e tipificou o fenômeno, da mesma forma como construiu e realizou a aplicação de questionários a uma quantidade de alunos. Foram estes conjuntos de ações levaram Olweus, em 1993, a publicar o livro Bullying at School. Este livro serviu como um guia para diversas pesquisas e modelo de projeto de intervenção em vários países (Olweus, 1973; Simmons, 2004). 
Este tipo de violência entre os diversos jovens nas escolas é um fenômeno social bastante relevante com grandes consequências emocionais, cognitivas e sociais. Este fenômeno, infelizmente, tem sido encontrado e observado nas escolas em todo o mundo, não diferente das escolas brasileiras (Guzzo, 2001; Lisboa \& Koller, 2001; Olweus, 1973).

A comunidade acadêmica brasileira só teve interesse em estudar o fenômeno do bullying em meados da década de 1980. No entanto apenas em 1997 é que aparecem os estudos iniciais sobre o processo de intimidação pela Professora Marta Canfield e seus colaboradores. Estudos estes que foram apoiados na metodologia parecida com desenvolvida por Olweus, questionários aplicados a uma grande população de alunos em escola pública da cidade de Santa Maria, no Rio Grande do Sul (Fante, 2005a, Olweus, 1973).

\section{$\mathrm{O}$ termo bullying não possui} tradução literal para o português. No Brasil são utilizados os seguintes termos para referenciar este fenômeno: "maus tratos entre pares" ou "vitimização". Bully é o termo em inglês que sugere um sujeito "valentão" e bullying poderia ser traduzido como uma proposta de intimidação, o que de certa forma reduziria a complexidade do fenômeno a uma das suas várias formas de manifestação, ou seja, o comportamento de ameaças e intimidações. Utilizar o termo no idioma em inglês, juntamente ao processo de conceituação, permite abarcar a complexidade do processo (Braga \& Lisboa, 2010).

O bullying tem como características a ocorrência de ações agressivas, intencionais, repetitivas e sem motivação aparente que causam dor, angústia ou intimidação. $O$ que propicia a ocorrência do bullying é a existência de um desequilíbrio de poder entre o agressor e a vítima, e se deve ao fato de o agredido não conseguir se defender, por não ser tão forte quanto o agressor ou por possuir características psicológicas ou físicas que o tornam alvo de discriminação (Fante, 2005b, p. 41).

É necessário especificar que existem diversas definições para o significado de bullying, mas o termo se refere às ações que propositadamente acontecem causando prejuízos às pessoas, isto é uma forma de situação entre os pares, de maneira que um indivíduo exerce a dominância sobre o outro. As diversas características de uma pessoa, como a orientação sexual, etnia entre outras a tornam um alvo da situação de bullying. O fenômeno é classificado por diferentes formas: físico, relacional, verbal ou ainda cyberbullying (Berger, 2007a). 
As formas físicas são as mais diversas situações de agressão, como chutes, socos, empurrões e outros. A intimidação relacional acontece quando um colega não permite que o outro se socialize com os demais do grupo, o que é muito comum porque na puberdade acontece o aprimoramento destas habilidades sociais entre os adolescentes e a aprovação entre eles é parte essencial. O tipo verbal é a mais comum das intimidações e o seu avanço acontece com o passar da idade, sendo as suas características as ofensas através de apelidos e insultos. Existe também o cyberbullying marcado pelos ataques através das mensagens enviadas pela internet: redes sociais, salas de bate papo, imagens. $\mathrm{O}$ agressor se utiliza dos diversos meios da internet para intimidar a sua vítima (Berger, 2007b).

Outro fator da intimidação é a frequência do acontecimento. Frequência esta que irá variar conforme os países, as suas regiões e até mesmo as escolas de um mesmo bairro. Um dos fatores de sustentação desta influência encontra-se na variação cultural. Numa mesma escola poderemos encontrar uma frequência diferenciada de intimidação, pois a linguagem utilizada pelos adolescentes segue uma variação, mas que abrange um mesmo contexto se tornando bem similar (Fante, 2008a).
O bullying envolve três tipos de atores: 1) as vítimas da agressão, isto é, o agente passivo que sofre a agressão; 2) os agressores, agentes da ação; 3) as testemunhas, os que assistem coniventes, incentivando ou com medo, sem participar diretamente do ato de violência. (Silva, 2010).

Ainda de acordo com Silva (2006), existem três tipos de vítimas: a típica, a provocadora e a agressora. A típica é, em geral, tímida, submissa, pouco sociável, com aspectos físicos frágeis e dificuldades de se impor. "Essas crianças estampam suas inseguranças na forma de sensibilidade, passividade, submissão, falta de coordenação motora, baixa autoestima, ansiedade excessiva e dificuldades de se expressar" (Silva, 2006, p. 38).

Para prevenir ou enfrentar o bullying ou qualquer outro tipo de violência que ocorre no contexto escolar, não se deve partir de receitas prontas e fechadas, pois cada escola possui uma realidade específica, onde são construídas relações diferenciadas entre os membros. Sendo assim, o bullying também irá se apresentar de formas diferentes em cada contexto, não devendo, portanto, ser avaliado de modo descontextualizado. (Freire \& Aires, 2012, p. 57).

A revisão bibliográfica de literatura para este estudo teve como objetivo buscar uma reflexão sobre a ocorrência do 
fenômeno bullying, verificando os efeitos que ele pode causar na vida do indivíduo. Para isto foram utilizadas as seguintes palavras chaves para esta pesquisa: bullying, coping, resiliência, autoimagem, autoestima, violência, nos seguintes sites:

Scielo: http://www.scielo.org/php/index.php; Google Acadêmico: https://scholar.google.com.br/ e, Redalyc: http://www.redalyc.org/.

Ao longo desta revisão foram encontrados mais de sessenta artigos relacionados ao tema, sendo selecionados em torno de vinte e cinco artigos para este estudo, que retratam a violência e mostram o quanto este fenômeno tem crescido, não apenas no ambiente escolar, mas em diversos outros contextos da sociedade. Apesar de muitas pessoas pensarem que é um assunto que ganhou uma repercussão mais ampla nos dias atuais, vale salientar a necessidade de entender o que é o processo de violência causado pelo bullying e o porquê é tão comentado.

Portanto o bullying é para a criança um estressor ou problema cuja resolução na maioria das vezes se apresenta como fora do controle para solução e, com isto dificulta todo o processo de adaptação saudável à escola. Os problemas de adaptação na escola podem ser alguns requisitos (indicadores) para o desenvolvimento seguinte, ocasionando comportamentos desadaptados ou outras patologias mais severas na adolescência e vida adulta. Desta forma as estratégias de coping eficazes para lidar com o bullying promovem adaptação e desenvolvimento saudáveis e podem ser consideradas como um fator de promoção de resiliência (Ladd, Buhs \& Troop, 2002). Socialmente o problema do bullying tem sido negligenciado, apesar da dimensão e das consequências, pois na visão de muitos adultos este fenômeno é um processo inevitável na vida escolar e que deve ser encarado como uma questão que faz parte da iniciação à vida adulta. A intimidação e a vitimização são de grande complexidade e se reproduzem nas relações sociais e com bem mais frequência no meio escolar, podendo agravar de forma progressiva o problema com repercussões a médio e longo prazo para todos os implicados (Freire et al., 2012; Lopes Neto, 2005; Mascarenhas, 2006; Pizarro \& Jiménez, 2007).

De acordo com Cantini (2004) a escola desempenha um papel de importância fundamental no desenvolvimento social de crianças e adolescentes, pois constitui um espaço de convivência e aprendizagem, oportunizando a socialização de jovens na cultura ocidental moderna. É a escola quem proporciona estas relações de hierarquia, vivências de igualdade e do convívio com as diferenças que farão parte da estruturação da formação do sujeito (Cantini, 2004). 


\section{BLOGS DA INTERNET}

Conforme Lisboa e Koller (2003) especificam, as interações que ocorrem no contexto escolar são caracterizadas pela forte atividade social. É nesse ambiente que as crianças e os adolescentes têm a oportunidade de expandir sua rede de interações e relações para além da família, desenvolvendo autonomia, independência e aumentando sua percepção de pertencer ao contexto social. As habilidades sociais, juntamente com as características de personalidade, contribuem para determinar a forma com que o indivíduo se relaciona com seus pares e tal aprendizagem serve como um treinamento para o convívio em sociedade (Lisboa \& Koller, 2003).

Ainda o ambiente escolar serve como cenário dos mais diversos processos e fenômenos grupais, como por exemplo, a violência escolar, que não é um problema recente, nem tampouco um fenômeno novo. Esta surge na interação social e pode ser definida como todo comportamento que visa causar danos ou prejuízos a alguém (Lisboa, 2005a).

Ainda levando em conta os relatos de Lisboa (2005b), o bullying é relevante para a psicologia, pois o comportamento agressivo pode ser considerado um processo decorrente da interação que ocorre entre a pessoa e o seu ambiente físico, social e cultural através do tempo, uma vez que emerge na interação social. Dessa forma, a referida autora aponta que é possível afirmar que uma criança está agressiva e não que ela é agressiva (Lisboa, 2005b).

Segundo relatos do Hawley (1999) alguns comportamentos agressivos são esperados durante o período da adolescência e com isto podem até mesmo ter benefícios adaptativos. No entanto, a agressão entre os pares não deve ser negligenciada ou tratada como parte do desenvolvimento, porque o bullying é um problema sério e pode trazer consequências graves aos envolvidos (Hawley, 1999).

Pesquisas têm associado à experiência de vitimização a diversos fatores, como: baixa autoestima, sintomas físicos e emocionais, ansiedade, medo, cefaleia, enurese, evitação escolar, depressão, ideias suicidas e suicídio, dentre outros. Ainda os efeitos do envolvimento em bullying podem persistir por toda a vida escolar e durante a vida adulta (Bandeira, 2009; Berger, 2007; Cantini, 2004; Lopes, 2005; Olweus, 1973).

Ainda, os estudos de Rolim (2008) apontam que o momento de maior incidência dos episódios de bullying e violência escolar ocorrem entre os nove e os quinze anos de idade e que o período da adolescência é identificado na literatura como sendo o período de maior ocorrência do bullying (Rolim, 2008).

Portanto com base em todas as considerações apresentadas este estudo teve por objetivo realizar uma análise dos relatos 
dos adolescentes, encontrados nos vários blogs da internet, para compreender os significados e sentidos produzidos por adolescentes acerca das práticas de intimidação vivenciadas.

\section{Método}

\section{Amostra}

Foram utilizados na pesquisa 61 relatos de adolescentes vítimas de bullying com idade entre 16 e 18 anos, de diversas escolas brasileiras, sendo 39 relatos do sexo masculino e 22 do sexo feminino, que cursavam o ensino médio, conforme os relatos analisados. Os participantes foram escolhidos a partir do critério básico de terem sido vítimas, ou seja, que haviam passado pela violência do bullying.

\section{Procedimentos}

Neste processo da pesquisa foram realizadas as buscas por blogs da internet que apresentaram relatos sobre o fenômeno do bullying. Para encontrar estes dados foram utilizadas as seguintes palavras chaves: bullying, coping, resiliência, autoimagem, autoestima, mobbing, violência escolar, abuso emocional, abuso físico e termos similares. Os dados utilizados para esta pesquisa foram os relatos de adolescentes vítimas de bullying encontrados nos seguintes blogs e sítios da internet: 1.http://oglobo.globo.com/sociedade/educa cao/veja-aqui-outros-relatos-de-pessoasque-sofreram-bullying-na-escola-3122758; 2. http://cafe-no bullying.blogspot.com.br/p/depoimentosde-pessoas-que-sofreram.html; 3.http://ceedmundoperaltabernades.blogsp ot.com.br/2011/10/depoimentos-depessoas-que-sofreram-o.html; 4.http://bullindocomobullying.blogspot.co m.br/2009/04/depoimentos-de-vitimas-dobullying.html

Ao todo foram encontrados 232 relatos sobre o assunto, no entanto foram retirados 171 depoimentos, porque estes eram de adolescentes que não tinham sido vítimas de bullying, mas conheciam outras pessoas que teria passado por tal situação. Portanto, para efeito da pesquisa foram utilizados apenas os relatos dos adolescentes que sofreram bullying, nos últimos cinco anos. Este critério foi escolhido para que apenas fossem analisados depoimentos mais recentes deste fenômeno.

\section{Análise de Dados}

Foi realizada a análise de conteúdo temática que conforme especificado por Bardin (2009) compreende as seguintes etapas: a) Pré-análise (fase de organização que teve por objetivo operacionalizar e 
sistematizar as ideias iniciais de maneira a conduzir a um esquema preciso de desenvolvimento da pesquisa; b) exploração do material (é a operação de analisar o texto sistematicamente em função das categorias formadas anteriormente; e c) tratamento dos resultados, inferência e interpretação. Os resultados brutos, ou seja, as categorias utilizadas como unidades de análise foram submetidas de acordo com as frequências encontradas de maneira que permitissem ressaltar as informações obtidas (Bardin, 2009).

Tabela 1
Inicialmente foi realizada a leitura flutuante de todos os depoimentos diversas vezes para que as categorias fossem identificadas. Com a definição realizada foram especificados o exemplo e a frequência de aparecimento desta categoria nos vários relatos de adolescentes vítimas de bullying. A Tabela 1 a seguir apresenta as cinco categorias formuladas, com respectivas definições operacionais e um exemplo ilustrativo.

Descrição das Categorias, Definições Operacionais e Exemplos de Relatos.

\begin{tabular}{|c|c|c|}
\hline Categoria & Definição Operacional & Exemplo \\
\hline $\begin{array}{l}\text { 1. Agressão } \\
\text { Verbal }\end{array}$ & $\begin{array}{c}\text { Atitude dirigida à vítima que } \\
\text { envolve xingamentos, ironias e } \\
\text { ofensas de forma a desqualificar o } \\
\text { sujeito }\end{array}$ & $\begin{array}{l}\text { "Chamavam de "macaco", me } \\
\text { desprezavam por minha cor" }\end{array}$ \\
\hline $\begin{array}{l}\text { 2. Violência } \\
\text { Física }\end{array}$ & $\begin{array}{c}\text { Procedimento de agressão que } \\
\text { envolve: chutes, socos, tapas, puxar } \\
\text { cabelo de forma a intimidar a } \\
\text { vítima. }\end{array}$ & $\begin{array}{l}\text { "Perdi } 5 \text { dentes, arranhão de } \\
\text { córnea, tive trauma craniano } \\
\text { e uma fratura na perna" }\end{array}$ \\
\hline $\begin{array}{l}\text { 3. Intimidação } \\
\text { pela Internet }\end{array}$ & $\begin{array}{l}\text { Ato executado pelo agressor com } \\
\text { relação a divulgação de ameaças, } \\
\text { ofensas e outras situações pela } \\
\text { internet. }\end{array}$ & $\begin{array}{l}\text { "Por ser gorda sou gozada, } \\
\text { até no computador" }\end{array}$ \\
\hline $\begin{array}{l}\text { 4. Intimidação } \\
\text { relacional }\end{array}$ & $\begin{array}{l}\text { Situação que o agressor realiza } \\
\text { impedindo que outras pessoas se } \\
\text { relacionem com a vítima }\end{array}$ & $\begin{array}{c}\text { "Não queriam que eu entrasse } \\
\text { nas brincadeiras deles" }\end{array}$ \\
\hline $\begin{array}{l}\text { 5. Violência } \\
\text { sexual }\end{array}$ & $\begin{array}{l}\text { Forçar a vítima a ter relação sexual } \\
\text { como forma de intimidação }\end{array}$ & "Abusam sexualmente de mim" \\
\hline
\end{tabular}




\section{Resultados}

A primeira categoria, que mais aparece nos relatos com cinquenta e quatro citações, é a agressão verbal. Esta apresenta relatos dos adolescentes especificando as mais variadas formas de agressão verbal sofrida (ofensas, xingamentos e apelidos). A vítima é escolhida muitas vezes como um bode expiatório da situação. $\mathrm{O}$ grupo intimidador escolhe alguém ao acaso e começa a tratá-los mal de forma a fazer valer o processo de intimidação.

Normalmente este tipo de agressão não parte apenas de um adolescente específico estando na maioria das vezes em grupo, o que aumenta a incidência do fenômeno. Neste relato podemos verificar que o adolescente é agredido, verbalmente, repetidas vezes, por vários outros adolescentes sem conseguir reagir a esta ação: "Quando eu ia pra escola tinham uns meninos que me chamavam de "macaco", me desprezavam por minha cor. Na rua os meus colegas ficavam me chamando de “frango", de feio, de otário...".

Os agressores, na maioria das vezes, se utilizam de plateias, além de estarem em grupos, para cometerem a violência, deixando a vítima completamente humilhada sem espaço para tomar qualquer atitude frente à situação. Este tipo de situação deixa a vítima de bullying mais vulnerável perante todos e, ao mesmo tempo retraída, não reage por receio do que possa acontecer, terminando por se isolar de todos: "Era atormentada por meninos infantis só por que eu era estranha e não me vestia bem. Chamavam-me de cabelo-deurso, olho de burca etc., entre muitos. Era quase sempre na frente de todo mundo, para eu me sentir muito humilhada e eles se sentirem melhor. Eu me lembro também deles terem muita plateia, que os achavam o máximo por eles fazerem aquilo”.

No relato que se apresenta verificamos que a agressão verbal também pode partir de um adulto que utiliza os mesmos meios que os demais adolescentes, público, para humilhar o outro. Este se utiliza do "poder" que tem como professor para fazer valer a usa autoridade de forma errada. Neste caso o adolescente teme ainda mais, pois há receio de sofrer punição: “Ano passado eu tinha um professor de educação física que me chamava de gnomo, isso me deixava muito chateada porque ele falava no meio de todo mundo".

Este tipo de agressão não é apenas por parte do gênero masculino, mas por ambos os sexos. As meninas também participam deste tipo de intimidação entre elas, escolhendo sempre alguma vítima que não gostem ou muitas vezes que seja quieta 


\section{BLOGS DA INTERNET}

para exercitar este tipo de agressão: "Bom desde sempre nunca tive amigas e até hoje não tenho, quase todo dia eu choro porque as garotas zoam muito comigo, na hora do recreio e sala; chama de feia, burra, cachorra louca”.

A segunda categoria delimitada é a violência física com vinte e seis citações. Nesta categoria podemos mostrar que existe uma relação com a agressão verbal, pois na maioria das vezes a agressão física é uma consequência da agressão verbal, pois quando o agressor se sente apoiado por outros, a tendência é cada ampliar a sua sede de intimidação, o que leve à agressão física: "Então eu era ainda meio inocente quanto às outras meninas da minha classe, e elas começaram a me zuar. No começo pra mim elas estavam brincando e nem davam bola, até que elas não satisfeitas de ficarem insultando, começaram a bater. Eram duas meninas. Foi indo eu sempre levava umas tapas na cara, uns puxões de cabelo, então uns moleques da minha sala começaram a fazer isso também. Eu não falei com os meus pais porque eles não iriam acreditar, eles achavam que pra alguém dar uma tapa em alguém tinha que ter feito alguma coisa".

Ainda, as outras pessoas que acompanham o agressor muitas vezes nada fazem por receio de se tornar a próxima vítima. Com isto o sentimento da vítima é de injustiça, apatia e não consegue fazer nada para mudar: “... ele veio e "bateu o tiro de meta" no meu rosto. Perdi 5 dentes, arranhão de córnea, tive trauma craniano $e$ uma fratura na perna...". O silêncio que é interpretado, pelo intimidador, como aprovação, seja através de risos ou outras situações pelo observador, neste caso, é tido como cúmplice da intimidação.

Entretanto o processo de agressão física acontece também entre gêneros diferentes. No caso do relato abaixo verificamos a agressão física de um adolescente por uma adolescente: "Olá, tenho 13 anos e sou vítima de bulliyng por parte de um rapaz... tudo isto começou há 4 anos...ele agarra-me pelos cabelos e atirame contra a parede até ficar cheia de sangue, a última vez que ele me fez isto (que foi ontem), ele agarrou-me pelo pescoço e atirou-me para o chão com toda a força...estou cheia de manchas negras e de feridas graves... tenho medo de ir para a escola... já é a segunda vez que eu mudo, mas ele sabe onde eu vivo e segue-me até casa...". Neste caso muitas vezes o agressor sente algo pela vítima, mas por não ter o apoio dos outros do grupo, que não o apoiam, a tendência dele é partir para a agressão, seja verbal ou física, perseguindo a vítima constantemente.

A terceira categoria denominada de "Intimidação pela internet", com a frequência de seis citações, tem se tornado bastante comum nos dias de hoje, pois as 
ofensas acontecem nas páginas das redes sociais das mais diversas formas: "O pior é que os outros colegas não faziam nada! $O$ extremo foi uma montagem que ele fez com uma foto minha, na última semana de aula. Eu nunca tive esse menino em nenhuma rede social, mas de algum jeito, ele achou o meu facebook, copiou minha foto e colocou um nariz de palhaço e um chifre. Depois, levou para a escola e ficou mostrando". Neste caso o agressor muitas vezes não tem coragem de agredir pessoalmente, se utiliza das redes sociais para fazê-lo. Com o avanço da tecnologia o bullying ganhou o seu espaço neste local. A violência e o processo de intimidação são os mesmos, pois muitos adolescentes têm a sua rede social invadida com ofensas e brincadeiras de mau gosto.

Na maioria das vezes o praticante do cyberbullying se esconde facilmente, sob uma identidade alternativa, virtual, fazendo com que se sinta seguro para praticar a violência sem sofrer reprimendas. Ou ainda, executa a ação, porque acredita que não será punido: "Mas recentemente houve um fato em minha escola que acho que vai gerar muitas brincadeiras de mau gosto referente a mim tudo isso graças a um vídeo que alguém que se dizia meu amigo fez (nunca liguei paras as famosas gracinhas dele, mas depois de um tempo começa ficar quase insuportável pra mim, a ponto de me deixar estressado com tudo e, quase todos, a minha volta) não quero que isso vá adiante porque ainda não está tão público assim...".

A quarta categoria denominada de "Intimidação relacional" apresentou um índice de menor prática com apenas duas citações. No entanto o agressor normalmente faz com que os demais colegas do grupo não mantenham nenhum tipo de contato daquela pessoa, vítima do fenômeno: "Para dizer a verdade nem sei bem porque não fazia mal nenhum a ninguém muito pelo contrário, tudo começou desde o primeiro ano e acabou no nono, discriminavam e não queriam que eu entrasse nas brincadeiras deles, tratavam me como se eu fosse um ser inferior...". A vítima deste tipo de intimidação não entende $o$ porquê do tratamento diferenciado e, com isto se isola de todos não conseguindo fazer amizade com os demais.

Este tipo de situação acontece através de bilhetes com ameaças a pessoa, fazendo com que ela não se aproxime dos demais colegas, pois isto pode acarretar problemas para o seu convívio no ambiente: "As agressões passaram de bilhetinhos a boatos sobre a orientação sexual, gestos puramente obscenos e todos os outros viravam a cara". A tendência é ampliar a forma de agressão saindo do relacional para gestos que intimidem a vítima até chegar à agressão física. Muitas vezes o intimidado 


\section{BLOGS DA INTERNET}

tenta manter uma relação de cordialidade buscando uma aproximação do grupo, mas é logo agredida, pois o agressor quer acima de tudo que a sua decisão seja acatada pelos demais sem nenhum questionamento. Por isso na maioria das vezes o intimidado tenta manter distância do grupo evitando confronto que resultará em outros problemas, como a agressão física.

A quinta categoria denominada de "Violência Sexual", apesar de ter aparecido apenas dois casos é outro tipo de agressão presente neste processo de violência. A vítima é acuada e termina por ser violentada. Por vergonha não conta para ninguém e a situação torna a acontecer: “Abusam sexualmente de mim, mas tenho vergonha de contar a alguém, mas como aqui é anônimo ninguém sabe, espero que me ajudem”. A vítima indefesa pratica a lei do silêncio, pois o agressor ameaça muitas vezes, contar a outros o que o intimidado fez, tornando a pessoa alvo de gozação.

Muitas vezes a vítima deste tipo de situação não consegue contar para a família o que está acontecendo por receio de ser mal interpretado e, ainda passar de vítima a culpado: “... há um aluno na escola que me bate sempre que não levo dinheiro, $e$ quando levo dinheiro diz que é pouco e me bate, uma vez até me obrigou a fazer-lhe coisas indecentes...". A vítima é intimidada de diversas formas e, quando não obedece ao que foi imposto pelo agressor sofre as penalidades.

Os dois casos que apareceram nos relatos analisados foram com garotos. Então o agressor não faz distinção de quem será a sua próxima vítima. Basta que ele encontre formas de intimidar e manter aquela pessoa no seu controle.

\section{Discussão}

Conforme as análises realizadas verificamos que adolescentes vítimas da violência do bullying permanecem em silêncio por medo de ser novamente ofendidos. Com isto buscam o isolamento dos demais colegas evitando o contato com aqueles que o agridem verbalmente buscando passar despercebido perante todos. Os que presenciam este tipo de procedimento nada fazem, terminando por apoiar de certa forma, por temer na maioria das vezes se tornarem a próxima vítima da agressão.

De acordo com Berger (2007c) o bullying verbal é a mais comum das intimidações, sendo as suas principais características as ofensas através de apelidos, insultos, xingamentos e outras situações. Com o passar do tempo à tendência é avançar ampliando as suas características.

Os dados encontrados nesta pesquisa confirmam o que a literatura 
retrata sobre o assunto, pois a violência verbal é uma das mais presentes entre as situações de bulliyng. Os adolescentes normalmente se utilizam deste artifício para mostrarem a sua dimensão de poder e com isto tornar o processo de agressão constante.

Segundo Fante (2008b), numa mesma escola poderemos encontrar uma frequência diferenciada deste tipo de intimidação, pois a linguagem utilizada pelos adolescentes segue uma variação, mas que abrange um mesmo contexto se tornando bem similar.

Ao longo da pesquisa, esta afirmação de Fante, pode ser verificada, pois vários são as formas de intimidação utilizadas pelos adolescentes. Depende do ambiente e o seu objetivo em atingir a sua vítima.

$\mathrm{Na}$ maioria das vezes a vítima permanece em silêncio por medo de ser novamente ofendida. E com isto busca o isolamento dos demais colegas e, evitando o contato com aqueles que o agridem verbalmente e, até mesmo de outras pessoas, buscando passar despercebido perante todos. Os que presenciam este tipo de procedimento nada fazem, terminando por apoiar de certa forma, pois temem na maioria das vezes se tornarem a próxima vítima da agressão.

Este processo, conforme informado por Fante (2005c) de intimidação não é apenas uma atitude realizada pelo público masculino, mas por ambos (masculino e feminino). Muitas pessoas pensam que o fenômeno da intimidação, com relação à violência física, só ocorre com os homens, mas as mulheres também participam deste tipo de situação.

Podemos ter esta visão na análise dos dados, porque é bem comum este tipo de procedimento entre o público feminino porque elas se utilizam desta forma de violência para marcar o seu espaço entre as demais pessoas.

A necessidade de controlar o outro e se sentir superior é bem característico do fenômeno. Com isto a pessoa que sofre a agressão sabe que não vai conseguir enfrentar este agressor, porque ao mesmo tempo existem outros que apoiam esta situação, uma vez que o agressor se encontra em grupos e, nunca sozinho.

Os resultados corroboram para esta afirmativa, pois em diversos discursos a tendência é partir para a agressão e, com isto controlar o outro fazendo a sua relação de poder se sobressair frente ao agredido. Ainda a vítima, na maior parte das vezes, não revida por medo que a agressão continue com uma maior dimensão.

Sendo assim o intimidado evita os confrontos diretos e se mantém em posição de isolamento. Muitas vezes não fala nada para ninguém por sentir medo da agressão aumentar ou às vezes, por gostar do agressor e, achar que este mudará a sua 
atitude. $\mathrm{O}$ intimidado raciocina entre o fazer e o dizer, levando em conta as circunstâncias, resultando em negociações internas que conduz a sua vida e a dos outros.

De acordo com o Fante (2005d), o que propicia esta ocorrência é a existência de um desequilíbrio de poder entre o agressor e a vítima, e se deve ao fato de o agredido não conseguir se defender, por não ser tão forte quanto o agressor ou por possuir características psicológicas ou físicas que o tornam alvo de discriminação. Ainda, as formas físicas encontradas são as mais diversas situações de agressão, como chutes, socos, empurrões, brigas e outros.

Neste caso o agressor muitas vezes não tem coragem de agredir pessoalmente, se utiliza das redes sociais para fazê-lo. Com o avanço da tecnologia o bullying ganhou o seu espaço neste local. A violência e o processo de intimidação são os mesmos, pois muitos adolescentes têm a sua rede social invadida com ofensas e brincadeiras de mau gosto.

Muitas vezes a vítima não acredita que algo pior possa acontecer e, então quando percebe a sua página, na rede social já foi invadida e a violência implantada. É mais uma forma do agressor fazer valer a sua superioridade.

Este discurso caracteriza o que o Berger relata da existência do cyberbullying marcado pelos ataques através das mensagens enviadas pela internet: redes sociais, salas de bate papo, imagens. O agressor se utiliza dos diversos meios da internet para intimidar a sua vítima (Berger, 2007d).

A vítima deste tipo de intimidação não entende $\mathrm{o}$ porquê do tratamento diferenciado e, com isto se isola de todos não conseguindo fazer amizade com os demais. Porém este tipo de procedimento é um reflexo do agressor que ameaça as pessoas do seu grupo para não manterem laços de amizade de forma alguma com aquelas pessoas. Os demais membros do grupo obedecem e passam a ignorar a vítima por receio de se tornarem mais um alvo daquele intimidador.

De acordo com o Berger, a intimidação relacional acontece quando um colega não permite que o outro se socialize com os demais do grupo, o que é muito comum porque na puberdade acontece o aprimoramento destas habilidades sociais entre os adolescentes e a aprovação entre eles é parte essencial. (Berger, 2007e)

Porém este tipo de procedimento é um reflexo do agressor, conforme os dados apresentados, pois acontece a ameaça das pessoas do seu grupo para não manterem laços de amizade de forma alguma com aquelas que são agredidas. Desta forma os demais membros do grupo obedecem e passam a ignorar a vítima por receio de se 
tornarem mais um alvo daquele intimidador.

De acordo com o Fante (2005e), o que propicia esta ocorrência é a existência de um desequilíbrio de poder entre o agressor e a vítima, e se deve ao fato de o agredido não conseguir se defender, por não ser tão forte quanto o agressor ou por possuir características psicológicas ou físicas que o tornam alvo de discriminação.

No caso de violência sexual a vítima deste tipo de intimidação poderá passar por todas as situações já descritas (verbal, física, relacional, cyberbullying). Verbal pelas ofensas que recebe por ter sido vítima da violência sexual, passando a ser classificada e apontada com nomes ofensivos, pois o agressor termina por contar ao seu grupo e espalhar boatos sobre a vítima. Físico, porque a vítima sofreu agressão para ser submetida a este tipo de intimidação, sendo machucada, chutada ou outras situações.

A pesquisa confirma isto, porque na maioria das vezes a vítima já passou por todas as outras violências até chegar a agressão sexual. Esta é uma forma de manter a vítima isolada não reagindo a quaisquer que sejam as situações de agressão.

No caso do relacional o agressor conta como um ato de poder para as demais pessoas e ameaça para que ninguém tenha contato com a vítima. Até ameaça os demais do grupo, caso alguém se aproxime da vítima.

Em relação ao cyberbullying muitas vezes a vítima tem a sua vida invadida nas redes sociais sofrendo todos os tipos de agressão e divulgação sobre o ocorrido. Claro que o agressor se esconde atrás de um anonimato, pois sabe que pode ser descoberto e punido.

É bem comum este tipo de situação de acordo com os dados pesquisados, porque a tendência nos dias atuais é agredir o outro de forma anônima (internet/redes sociais diversas) e, com isto não ser descoberto pelo outro. Quando descoberto utiliza dos demais métodos de agressão para continuar com a cadeia de violência.

Sendo assim de acordo com Freire e Aires (2012) para prevenir ou enfrentar o bullying ou qualquer outro tipo de violência que ocorre no contexto escolar, não se deve partir de receitas prontas e fechadas, pois cada ambiente possui uma realidade específica, onde são construídas relações diferenciadas entre os membros. Sendo assim, o bullying também irá se apresentar de formas diferentes em cada contexto, não devendo, portanto, ser avaliado de modo descontextualizado (Freire \& Aires, 2012).

\section{Considerações Finais}

Esta pesquisa não teve por objetivo buscar conclusões acerca deste assunto, mas 
ampliar o leque de discussões sobre o tema abordado. A intenção era compreender como ocorre o fenômeno entre os adolescentes e as suas percepções frente ao bullying no contexto escolar.

Desta forma foi possível verificar que este fenômeno só tem crescido nos ambientes escolares e demais locais da sociedade, pois a exigência das pessoas por um determinado padrão social direciona a construção de todo um processo de violência física e verbal, seja nas relações diretas ou muitas vezes pela internet, pois muitos ainda acreditam ser um campo no qual possam fazer uso para agredir as pessoas e ficar muitas vezes no anonimato.

Desta forma ao mesmo tempo que acreditamos que a escola deveria ser espaço de conhecimento e de interação social entre os vários adolescentes, esta funciona como um ambiente de violência e situações adversas.

A psicologia pode ajudar diante desta situação de sofrimento auxiliando nos diversos processos identificando os que sofrem seja como vítima ou agressor e dando o apoio necessário. Apenas desta forma será possível construir espaços de menos violência, quando existe o apoio necessário dos diversos campos da sociedade.

Portanto este não é um estudo definitivo, mas com o pensamento que outras pesquisas assim como as que serviram de embasamento para esta possam auxiliar no processo de criar num futuro próximo indivíduos mais seguros e com entendimento das questões sociais e, com isto podendo construir uma sociedade de maior tolerância e cultura de paz.

\section{Referências}

Bandeira, C. M. (2009). Bullying: autoestima e diferenças de gênero. Dissertação de Mestrado não publicada, Instituto de Psicologia, Universidade Federal do Rio Grande do Sul, Porto Alegre.

Bardin, L. (2009). Análise de conteúdo. Lisboa: Edições 70.

Berger, K. S. (2007). Update on bullying at school: Science forgoten? Developmental Review, 27, 90-126. DOI 10.1016/j.dr.2006.08.002.

Braga, L. de L. \& Lisboa, C. (2010). Estratégias de Coping para Lidar com o Processo de Bullying: Um Estudo Qualitativo. Revista Interamericana de Psicologia/ Interamerican Journal of Psychology, 44(2), 321-331.

Cantini, N. (2004). Problematizando o bullying para a realidade brasileira. Dissertação de Mestrado não publicada, Programa de Pós-Graduação em Psicologia do Centro de Ciências da Vida, Pontifícia Universidade Católica de Campinas, Campinas, São Paulo. 
Fante, C. (2005). Fenômeno bullying: como prevenir a violência nas escolas e educar para a paz. São Paulo: Versus.

Fante, C. (2008). Brincadeiras perversas. Viver Mente e Cérebro, ano XV, 181, 74-79.

Freire, A. N. \& Aires, J. S. (2012). A contribuição da psicologia escolar na prevenção e no enfrentamento do bullying. Revista Psicologia. Escolar e Educacional, 16(1), 55-60. DOI 10.1590/S1413-85572012000100006.

Guzzo, R. (2001). Saúde psicológica, sucesso escolar e eficácia na escola: Desafios do novo milênio para a psicologia escolar. In Z. A. P. Del Prette (Ed.), Psicologia escolar $e$ educacional: Saúde e qualidade de vida (pp. 25-42). Campinas, SP: Alínea.

Hawley, P. H. (1999). The ontogenesis of social dominance: A strategy-based evolutionary perspective. Developmental Review, 19, 97-132. DOI 10.1006/drev.1998.0470.

Ladd, G., Buhs, E., \& Troop, W. (2002). Children's interpersonal skills and relationship in school settings: Adaptive significance and implications for school based prevention and intervention programs. Em P.K. Smith \& C.H. Hart. Blackwell handbook of childhood social development (pp. 394-415). Padstown: Backwell.

Lisboa, C., \& Koller, S. (2001). O microssistema escolar e os processos proximais: Exemplos de investigações científicas e intervenções práticas. Em S. Koller. (Ed.), Ecologia do desenvolvimento humano: Pesquisa e intervenção no Brasil (pp. 337-353). São Paulo, SP: Casa do Psicólogo.

Lisboa, C., \& Koller, S. H. (2003). Interações na escola e processos de aprendizagem: fatores de risco e proteção. Em E. Boruchovitch \& J. A. Bzuneck (Eds.), Aprendizagem: processos psicológicos e o contexto social na escola (pp. 201-224). Petrópolis, RJ: Vozes.

Lopes, A. A. N. (2005). Programa de reducción del comportamiento agresivo entre estudiantes. Em C. B. Silva \& C. M. Lisboa (Eds.), Violência escolar (pp. 297-335). Santiago de Chile: Universitária.

Mascarenhas, S. (2006). Gestão do bullying e da indisciplina e qualidade do bem-estar psicossocial de docentes e discentes do Brasil (Rondônia). Psicologia, Saúde \& Doenças, 7(1), 95-107.

Olweus, D. (1973). Conductas de acoso y amenaza entre escolares ( $2^{\mathrm{a}}$ ed.). Madrid: Ediciones Morata.

Pizarro, H. C., \& Jiménez, M. I. (2007). Maltrato entre iguales en la escuela costarricense. Revista Educación, 31(1), 135-144. DOI 10.15517/revedu.v31i1.1258.

Rolim, M. (2008). Bullying: o pesadelo da escola, um estudo de caso e notas sobre o que fazer. Dissertação de Mestrado, Programa de Pós-Graduação em Sociologia, Instituto de Sociologia, Universidade Federal do Rio Grande do Sul, Porto Alegre.

Silva, A. B. B. (2010) Bullying: mentes perigosas nas escolas. Rio de Janeiro: Fontanar. 
Silva, G. de J. (2006) Bullying: quando a escola não é um paraíso. Jornal Mundo Jovem, s/d.

Simmons, R. (2004). Garota fora de jogo. A cultura oculta da agressão nas meninas (T. M. Rodrigues, Trad.). Rio de Janeiro: Rocco.

\section{Os autores:}

Jales Silva Barreto é graduando em Psicologia pelo Centro Universitário de Brasília, UniCEUB, e-mail" jales18@gmail.com

Marina Kohlsdorf é doutora e mestre em Processos de Desenvolvimento Humano e Saúde pelo Programa de PósGraduação em Processos de Desenvolvimento Humano e Saúde, no Instituto de Psicologia da Universidade de Brasília. Professora no curso de Psicologia do Centro Universitário UniCeub nos cursos de graduação e mestrado em Psicologia. Colaboradora no Laboratório de Desenvolvimento em Condições Adversas LADVERSA - na Universidade de Brasília (UnB). Editora associada da revista Psicologia: Reflexão e Crítica. E.mail: marinak@unb.br

Recebido em: 17/07/2017.

Aprovado em: 29/12/2017. 